\title{
Breaking rules for the right reasons? An investigation of pro-social rule breaking
}

\author{
JASON J. DAHLING ${ }^{*}$, SAMANTHA L. CHAU' ${ }^{2}$, \\ DAVID M. MAYER ${ }^{3}$ AND JANE B. GREGORY ${ }^{4}$ \\ ${ }^{1}$ The College of New Jersey, New Jersey, U.S.A. \\ ${ }^{2}$ Novo Nordisk Inc., New Jersey, U.S.A. \\ ${ }^{3}$ University of Michigan, Michigan, U.S.A. \\ ${ }^{4}$ Procter \& Gamble, Ohio, U.S.A.
}

\begin{abstract}
Summary Pro-social rule breaking (PSRB) is a form of constructive deviance characterized by volitional rule breaking in the interest of the organization or its stakeholders. Over the course of three studies, we developed a generalizable measure of PSRB and placed it in a nomological network with personality, workplace perceptions, counterproductive behaviors, and task and contextual performance ratings made by supervisors and coworkers. Results indicate that PSRB is negatively related to task performance ratings across both sources despite its pro-social motivation intended to help the organization. Potential directions for future research concerning reactions to constructive deviance are discussed. Copyright (C) 2010 John Wiley \& Sons, Ltd.
\end{abstract}

\section{Introduction}

Pro-social behavior has attracted considerable research attention over the last three decades (e.g., Brief \& Motowidlo, 1986; Grant, 2008; Organ, 1988; Puffer, 1987; Zellars, Tepper, \& Duffy, 2002). Contrary to the traditional economic view of employees as self-interested performers, this literature has identified situations in which organization members engage in constructive, socially desirable behaviors that benefit coworkers or the organization as a whole with little or no benefit to the self. For example, employees can choose to help coworkers complete their tasks, pay more attention to customers than is required, put forth extra effort at task completion, or serve as a good representative of their organization to outsiders (Brief \& Motowidlo, 1986).

However, very few researchers have acknowledged the possibility that pro-socially motivated employees might choose to break organizational rules to perform these beneficial behaviors. For example, consider a hypothetical waiter faced with an upset customer. A common response to this situation might be to give the customer a free appetizer or dessert in an attempt to salvage the situation and keep the customer satisfied. Even if giving away free food violates an organizational rule, in this context the rule breaking is in the greater interest of the organization; the customer is now appeased and is likely to remain a repeat customer, and the benefits of this continued business far outweigh the cost of the free item. Although hypothetical, this scenario reflects the reality of many daily choices in organizations that require employees to either follow the rules or to deviate in the interest of effectively responding to perceived demands from customers, coworkers, or tasks themselves (e.g., Chung \& Schneider, 2002; Schulz, 2003).

\footnotetext{
* Correspondence to: Jason J. Dahling, Department of Psychology, The College of New Jersey, 2000 Pennington Rd., Ewing, NJ 08628, U.S.A. E-mail: dahling@tcnj.edu
} 
Morrison (2006) referred to this type of volitional rule breaking in the interest of the organization or its stakeholders as pro-social rule breaking (PSRB). More specifically, she identified three different categories of PSRB that are common in organizations, namely PSRB to (1) more efficiently perform job duties for the organization, (2) help another employee with job-related duties, and (3) provide better customer service. Although PSRB is a new construct that has not yet received much research attention (Mayer, Caldwell, Ford, Uhl-Bien, \& Gresock, 2007), it fits within an emerging body of research that stresses the relevance of deviance that is committed with constructive intentions in mind (e.g., Galperin, 2003; Gino \& Pierce, in press; Spreitzer \& Sonenshein, 2003; Vardi \& Weitz, 2004; Warren, 2003). We believe that existing research on PSRB has been limited by the lack of a generalizable measure of this construct. Consequently, our purpose in this paper is to advance research on PSRB by developing a general, multidimensional measure of the construct and placing it in a nomological network of individual differences, workplace perceptions, behavioral correlates, and important organizational outcomes, such as performance ratings.

\section{Background and Measurement of PSRB}

PSRB occupies an important, but largely neglected position within existing frameworks of organizational deviance. Traditionally, deviance researchers have focused on self-interested, destructive forms of deviance in organizations (e.g., Robinson \& Bennett, 1995). In contrast, several authors have noted that the constructive, or positive, forms of deviance that employees commit with pro-social intentions have received far less research attention (e.g., Galperin, 2003; Warren, 2003). Spreitzer and Sonenshein (2004) elaborated on the construct definition of positive deviance, noting that positive deviance is characterized by voluntary divergence from organizational norms with honorable intentions to better the organization or its stakeholders. For example, depending on their motives, specific organizational behaviors that may be categorized as constructive deviance include task revision (Staw \& Boettger, 1990) and principled action (Worline \& Quinn, 2003).

Certain forms of deviance may be constructive in some circumstances and destructive in others, such as whistleblowing, the act of informing a third party about illegal or unethical practices occurring in the workplace (Vardi \& Weitz, 2004). A particular instance of whistleblowing would be evaluated as constructive if the underlying intention was honorable and in the broad interest of organizational stakeholders (e.g., a desire to warn shareholders of wrongdoing or take initial steps to redeem the company's self-image). In contrast, the same whistleblowing behavior would be evaluated as destructive if the underlying motives were vindictive or self-interested (e.g., a desire to get even for being fired or secure media attention and a positive public image for oneself by coming forward first). Consistent with these examples, honorable intentions and pro-social motivation underlie the distinction between constructive and destructive deviance (Spreitzer \& Sonenshein, 2004).

Morrison (2006) described several important characteristics of PSRB that clearly place this behavior within the realm of constructive, rather than destructive, deviance. First, PSRB is a form of rule-breaking that is conducted volitionally. PSRB involves the violation of top-down rules and policies set by the administration of an organization (Zhou, 1993) rather than the deviation from emergent and informal norms that develop within social groups (Levine \& Moreland, 1998). Furthermore, PSRB concerns the deliberate violation of explicit, active rules; violations committed accidentally out of ignorance, or violations of rules that are not enforced and are widely perceived as defunct, are not categorized as PSRB behaviors. Second, Morrison (2006) also emphasized that an instance of rulebreaking behavior is pro-social only if the primary motivation behind the behavior is to help the organization or its stakeholders in an honorable fashion. This definition separates PSRB from destructive forms of deviance that are motivated mainly or exclusively by self-interest or vindictiveness.

To date, only two empirical studies have tested hypotheses concerning PSRB. Morrison (2006) developed a set of vignette stimuli that she used to manipulate several hypothesized antecedents of PSRB. She then wrote a related measure of PSRB specific to the vignettes used in the study. Her results showed that participants were more likely to 
indicate that they would engage in PSRB if the job in the scenario was characterized by high autonomy and if the scenario noted that other employees had also engaged in PSRB in the past. Additionally, she found that self-reports of risk-taking propensity correlated positively with PSRB.

Mayer et al. (2007) built on these initial findings to study the customer-focused type of PSRB in greater detail. They adapted Morrison's (2006) vignettes and used her scale to examine the extent to which supervisor-subordinate relationship quality is related to PSRB to assist a customer. Consistent with their expectations, PSRB was positively related to supervisor-subordinate relationship quality, and this relationship was mediated by perceived support from the supervisor. Further, perceived policy fairness moderated the relationship between relationship quality and PSRB. Respondents were most likely to report that they would engage in customer-oriented PSRB if they had a high-quality relationship with a supervisor and if the rule that they were breaking was evaluated as unfair or unreasonable. Importantly, both Mayer et al. (2007) and Morrison (2006) studied PSRB relative to the experimental vignette scenarios and a measure specific to those scenarios that Morrison developed.

Additional research is needed to further explore the antecedents and consequences of PSRB. Evidence suggests that PSRB is relatively common in organizations; in one study, Morrison (2006) found that approximately 64 per cent of participants could give an example of rule breaking that they had committed that would be categorized as PSRB. Further, the different types of PSRB that Morrison identified have important implications for organizations. PSRB has the potential to improve the efficiency of employees, acquire and retain valued customers, and build social capital through enhanced helping directed toward coworkers. Despite these important implications, there has not yet been any research on PSRB in actual organizational settings, and a well-designed survey measure is necessary to advance such research. Consequently, we identified a need to develop a new measure of PSRB that assesses all three types of PSRB described by Morrison, is generalizable to different organizational settings, and can be administered in a self-report format to large groups of employees. This study describes the development and initial validation of such a measure, which we named the General Pro-Social Rule Breaking Scale (GPSRBS).

We adopted Hinkin's (1995) best practices for the development and validation of the GPSRBS. In the sections that follow, we begin by developing a content-valid item pool in Study 1 and subjecting this pool to exploratory factor analysis (EFA) to assess its factor structure. In Study 2, we provide evidence of the measure's stability with a confirmatory factor analysis (CFA) on a second sample and develop and test several hypotheses to place the measure in a nomological network of correlates and task performance. We present additional criterion-related validity evidence with a third sample in Study 3 to clarify where PSRB stands relative to other forms of performance.

\section{Study 1: Item Generation and Exploratory Factor Analysis}

\section{Method}

\section{Procedure}

We wrote a pool of 21 items, consisting of seven items intended to reflect each of the three types of PSRB identified by Morrison (2006): PSRB for improved efficiency, PSRB to assist a coworker, and PSRB to provide better customer service. Because these are very narrowly defined constructs, we were confident that we could ultimately capture the construct domain space of each with short, three-to-five-item sub-scales (Hinkin, 1995; Little, Lindenberger, \& Nesselroade, 1999). Thus, we deliberately oversampled the construct space in the interest of subsequently reducing the item pool to yield scales that demonstrated good internal consistency, adequate representation of the construct, and parsimonious length.

We began by subjecting the 21 -item pool to a content analysis by asking $15 \mathrm{Ph} . \mathrm{D}$. students in Industrial/ Organizational Psychology to sort the items. This procedure involves asking raters to use their deductive reasoning to categorize the randomized list of items on their a priori dimensions. High agreement between raters provides preliminary evidence of the content validity of an item pool (Hinkin, 1995). Our raters were provided with the 
dimension descriptions and examples generated by Morrison (2006) and asked to indicate if each item we developed fit best with the efficiency, customer service, or coworker assistance subscale, or none of the above. Raters were free to provide open-ended, written comments on any item. All of the raters were in 100 per cent agreement after sorting all 21 items. Consequently, the full item pool was subsequently provided to participants in the context of a larger survey study.

\section{Sample}

Our sample consisted of 179 employees in applicable positions recruited from a large university in the Midwestern United States. The mean age of the sample was 21.5. Respondents were 75 per cent female and 86 per cent Caucasian, 9 per cent African American, 1.7 per cent Hispanic, 1.7 per cent Asian American, and 1.7 per cent Native American, Pacific Islander, or Other. All respondents were employed in customer service and they worked an average of 27 hours per week with a mean tenure of 23.3 months. Participants were instructed to read each item carefully and to honestly indicate the extent to which they agreed or disagreed that each item described their workplace behavior. Responses were on a five-point scale ranging from 1: strongly disagree to 5: strongly agree.

\section{Results}

We began by conducting an EFA (Thompson, 2004) using principal axis factoring. Although the items that we generated were written to conform to the types of PSRB previously described, we opted to treat the item pool in an exploratory fashion in our first study in the event that other interpretable factors might emerge in the analysis. We opted to use an oblique rotation (direct oblimin) given our expectation that the different types of PSRB would be highly interrelated (Fabrigar, Wegener, MacCallum, \& Strahan, 1999). Further, we conducted a parallel analysis (Hoyle \& Duvall, 2004) to provide a more objective indication of the number of factors to retain instead of using more subjective criteria, such as the Kaiser criterion or a Scree test (Thompson, 2004).

The results of a parallel analysis indicate the maximum number of factors that a researcher should choose to interpret (Hoyle \& Duvall, 2004). Our results indicated that, at most, a four-factor solution should be interpreted. The pattern matrix for this solution is presented in Table 1 and the factor correlation matrix is shown in Table 2.

Our interpretation of the factors indicated that the first factor represented the coworker assistance type of PSRB, the third factor represented the efficiency type, and the fourth factor represented the customer service type. However, the second factor was a statistical artifact composed of reverse-scored items that all spoke to strict rule compliance (Hinkin, 1995; Schmitt \& Stults, 1985). Therefore, using Comrey and Lee's (1992) criterion of 0.33 as an acceptably strong loading, we eliminated three items for loading exclusively on the artifactual second factor. As shown in Table 1, a further four items were dropped for cross-loading on multiple factors above the 0.33 threshold. Thus, we concluded the EFA process with a three-factor solution. At this point, the efficiency subscale had five items, the coworker assistance subscale had five items, and the customer service subscale had four items.

We then proceeded to assess the internal consistency and inter-item correlations among the three subscales. Results indicated that we could improve the reliability of the coworker assistance subscale from $\alpha=0.88$ to 0.91 by removing one additional item that we judged to be conceptually redundant with the other items ("I am flexible with organizational policies to assist a colleague with a problem"). We therefore concluded Study 1 with a five-item subscale of PSRB for efficiency reasons $(\alpha=0.87)$, a four-item subscale of PSRB for coworker assistance reasons $(\alpha=0.91)$, and a four-item subscale of PSRB for customer service reasons $(\alpha=0.86)$. All retained items are presented in boldface text in Table 1. The overall scale exhibited high internal consistency $(\alpha=0.93)$.

\section{Discussion}

Study 1 concluded with a 13-item, generalizable measure of PSRB. This scale can be broken into three content-valid subscales to focus on particular types of PSRB in organizations. Initial evidence based on a sorting exercise and an 
Table 1. Pattern matrix from exploratory factor analysis of GPSRBS item pool, Study 1

\begin{tabular}{|c|c|c|c|c|}
\hline & \multicolumn{4}{|c|}{ Factor } \\
\hline & $\begin{array}{c}1 \\
\text { (Coworker Aid) }\end{array}$ & $\begin{array}{c}2 \\
(\text { Artifact) }\end{array}$ & $\begin{array}{l}3 \\
\text { (Efficiency) }\end{array}$ & $\begin{array}{c}4 \\
\text { (Customer aid) }\end{array}$ \\
\hline $\begin{array}{l}\text { 1. I break organizational rules or policies to do my job } \\
\text { more efficiently }\end{array}$ & 0.09 & -0.04 & 0.71 & 0.11 \\
\hline $\begin{array}{l}\text { 2. I follow organizational policies, even if it makes me a less } \\
\text { efficient worker (R) }\end{array}$ & 0.12 & 0.52 & -0.34 & 0.00 \\
\hline $\begin{array}{l}\text { 3. I violate organizational policies to save the company } \\
\text { time and money }\end{array}$ & 0.14 & 0.00 & 0.64 & 0.15 \\
\hline $\begin{array}{l}\text { 4. I ignore organizational rules to "cut the red tape" and } \\
\text { be a more effective worker }\end{array}$ & 0.15 & 0.05 & 0.69 & 0.08 \\
\hline $\begin{array}{l}\text { 5. When organizational rules interfere with my job } \\
\text { duties, I break those rules }\end{array}$ & 0.14 & 0.00 & 0.65 & 0.16 \\
\hline $\begin{array}{l}\text { 6. I disobey company regulations that result in } \\
\text { inefficiency for the organization }\end{array}$ & 0.22 & 0.11 & 0.41 & 0.23 \\
\hline $\begin{array}{l}\text { 7. I respect organizational rules, even though they may make } \\
\text { it harder for me to do my job effectively }(R)\end{array}$ & 0.12 & 0.61 & -0.44 & 0.06 \\
\hline $\begin{array}{l}\text { 8. I break organizational rules if my coworkers need help } \\
\text { with their duties }\end{array}$ & 0.72 & -0.13 & 0.18 & 0.05 \\
\hline 9. I avoid breaking rules, even if it would help a coworker (R) & -0.38 & 0.61 & -0.12 & 0.09 \\
\hline $\begin{array}{l}\text { 10. I am flexible with organizational policies to assist a } \\
\text { colleague with a problem }\end{array}$ & 0.47 & 0.06 & -0.02 & 0.16 \\
\hline $\begin{array}{l}\text { 11. I do not violate organizational regulations, even if } \\
\text { another colleague is in need }(\mathrm{R})\end{array}$ & -0.25 & 0.51 & 0.01 & 0.12 \\
\hline $\begin{array}{l}\text { 12. When another employee needs my help, I disobey } \\
\text { organizational policies to help him/her }\end{array}$ & 0.71 & -0.16 & 0.09 & 0.05 \\
\hline $\begin{array}{l}\text { 13. I assist other employees with their work by breaking } \\
\text { organizational rules }\end{array}$ & 0.69 & 0.00 & 0.15 & 0.14 \\
\hline $\begin{array}{l}\text { 14. I help out other employees, even if it means } \\
\text { disregarding organizational policies }\end{array}$ & 0.84 & 0.04 & 0.07 & 0.02 \\
\hline $\begin{array}{l}\text { 15. I break rules that stand in the way of good customer } \\
\text { service }\end{array}$ & -0.04 & -0.06 & 0.28 & 0.66 \\
\hline $\begin{array}{l}\text { 16. I give good service to clients or customers by ignoring } \\
\text { organizational policies that interfere with my job }\end{array}$ & 0.05 & 0.04 & 0.14 & 0.66 \\
\hline $\begin{array}{l}\text { 17. Even if it means providing poor customer service, I do } \\
\text { not disobey organizational rules (R) }\end{array}$ & 0.03 & 0.71 & 0.24 & -0.23 \\
\hline $\begin{array}{l}\text { 18. I break organizational rules to provide better } \\
\text { customer service }\end{array}$ & 0.07 & -0.10 & 0.09 & 0.68 \\
\hline $\begin{array}{l}\text { 19. I bend organizational rules so that I can best assist } \\
\text { customers }\end{array}$ & 0.15 & -0.15 & 0.01 & 0.76 \\
\hline $\begin{array}{l}\text { 20. I assist customers by breaking organizational rules that } \\
\text { make good customer service difficult to provide }\end{array}$ & 0.34 & 0.01 & -0.07 & 0.57 \\
\hline $\begin{array}{l}\text { 21. I refuse to violate organizational regulations to give a } \\
\text { customer what they want }(\mathrm{R})\end{array}$ & 0.04 & 0.74 & 0.07 & -0.27 \\
\hline
\end{tabular}

Note: Primary loadings are in bold. Items retained in the final scale are presented in bold. (R) indicates reverse-scored items.

EFA suggests that the scale has appropriate content validity (Hinkin, 1995). Further, each subscale and the overall scale exhibited high reliability (Nunnally, 1978).

Following Hinkin's (1995) recommendations, we collected a separate sample in Study 2 after developing the GPSRBS in Study 1 with several objectives. First, we sought to confirm the factor structure of the scale to demonstrate its stability. Consistency in factor structure is an important prerequisite for the construct validity of 
Table 2. Factor correlation matrix, Study 1

\begin{tabular}{lrrrr}
\hline Factor & F1 & F2 & F3 & F4 \\
\hline F1 (Efficiency) & 1.00 & & & \\
F2 (Artifact) & -0.19 & 1.00 & 1.00 & \\
F3 (Coworker) & 0.41 & -0.23 & 0.39 & 1.00 \\
F4 (Customer) & 0.52 & -0.20 & & \\
\hline
\end{tabular}

multidimensional scales (Spector, 1992). Second, we developed and tested several hypotheses to provide initial evidence of the discriminant and criterion-related validity of the GPSRBS and to place it in a nomological network with related correlates. These hypotheses are developed in the sections that follow relative to a motivational framework developed by Vardi and Weitz (2004).

\section{Study 2: Confirmatory Factor Analysis and Validity Evidence}

\section{Hypothesis development}

\section{Relationships with personality and normative expectations}

In the absence of much existing research on PSRB, we turned to a related theoretical framework developed by Vardi and Weitz (2004) to select constructs for our nomological network. Vardi and Weitz's framework categorizes organizational misbehavior (OMB) into three types. Their OMB Type-D ("destructive") concerns misbehavior motivated by an intention to damage the organization and seek retribution, whereas OMB Type-S ("self") involves misbehavior conducted for personal gain, such as theft. Both Type-D and Type-S misbehaviors are treated as forms of destructive deviance by other authors (e.g., Robinson \& Bennett, 1995; Warren, 2003). In contrast, OMB Type-O ("organizational") reflects misbehaviors that are primarily intended to benefit the employing organization, and it is likely that PSRB would fit within this category of constructively deviant behavior. Vardi and Weitz point out that the vast majority of deviance research is focused on Type-D and Type-S misbehavior; only sporadic research attention has been directed toward any forms of Type-O misbehavior.

The three types of misbehavior in Vardi and Weitz's (2004) framework are distinguishable based on the motivations that give rise to each. Based on Fishbein and Ajzen's (1975) Theory of Reasoned Action, Vardi and Weitz (2004) suggested that intentions to engage in Type-D or Type-S misbehavior are motivated primarily by attitudes and instrumental forces, which reflect employees' beliefs about the anticipated value of these behaviors for the self. In contrast, Type-O misbehaviors are thought to arise due to normative forces, which refer to employees' internalized beliefs about the behaviors or outcomes that are expected by the organization. Importantly, internalized normative expectations about desirable conduct can develop from a variety of sources, which may contradict each other. For example, top-down job demands can shape normative expectations, but so can informal aspects of the social context, consistent with Social Information Processing Theory (Salancik and Pfeffer, 1978). Additionally, personal traits and values can shape the way that normative expectations are perceived (Jones, 1991). Accordingly, we focused on selecting predictors of PSRB that reflect different sources of normative expectations about workplace conduct.

Conscientiousness: Conscientious individuals are characterized by a trait tendency toward orderliness, deliberation, thoroughness, dependability, and self-discipline (Barrick \& Mount, 1991). Because conscientiousness involves a strong core of discipline and responsibility, conscientious people are sensitive to the formal expectations 
for behavior that are set by others and are less prone to engage in deviance from these expectations. For example, past research indicates that conscientiousness is typically the strongest negatively related, dispositional predictor of destructive deviance in the workplace (e.g., Cullen \& Sackett, 2003). Further, highly conscientious individuals have higher integrity test scores (Ones, Viswesvaran, \& Schmidt, 1993) and are less likely to engage in other dysfunctional forms of rule breaking (Ashton, 1998). Consistent with this body of research, we expect that conscientious employees will be reluctant to break rules even for pro-social reasons, and we therefore hypothesize a negative relationship between conscientiousness and PSRB.

Hypothesis 1: Conscientiousness will be negatively related to self-reported PSRB.

Job demands: Consistent with the idea that PSRB is an adaptive response to workplace demands, we expect that perceived job demands, such as inadequate time and difficult responsibilities (Karasek, 1979), will encourage PSRB. Employees who report high job demands perceive that their organizations expect them to be highly productive with limited support, which may encourage them to break rules to meet these expectations. For example, intense time demands may create a greater need for efficiency (e.g., taking short-cuts) or cooperation with others in ways that are not officially sanctioned by the organization, but that seem consistent with the organization's expectations for successful performance. Concurrently, high job demands may also sap the self-regulatory resources that would normally inhibit rule-breaking behavior, resulting in more PSRB when demands are high (Marcus \& Schuler, 2004). Accordingly, we expect that the likelihood of PSRB will be greater when perceived job demands are high.

Hypothesis 2: Perceptions of job demands will be positively related to self-reported PSRB.

PSRB performed by others: Morrison (2006) provided some initial evidence that employees are more likely to commit PSRB if they are aware of other employees engaging in similar behavior. Specifically, in the context of her vignette study, she manipulated coworker behavior by including a statement that read, " . . you have heard through the grapevine that other customer service representatives have sometimes violated this policy in the past," a reference to the same rule that the participant was asked to consider violating. In the present study, we expected to replicate Morrison's (2006) findings in a self-report context. Research indicates that employees monitor the workplace environment to determine how potentially risky behavior is evaluated by others, and particularly whether or not such behaviors carry undesirable social consequences (Ashford, Rothbard, Piderit, \& Dutton, 1998; Dutton, Ashford, O'Neill, Hayes, \& Wierba, 1997; Robinson \& O'Leary-Kelly, 1998). This form of social learning helps to set and modify organizational expectations in ways that can encourage PSRB when others commit it. Accordingly, employees' perceptions of PSRB performed by others should communicate that such rule-breaking behaviors, while not officially sanctioned, are at least not excessively risky. We therefore predict that the focal employee's perceptions of PSRB committed by others on the job will relate positively to his or her own self-reported propensity to engage in PSRB.

Hypothesis 3: Perceptions of PSRB performed by others will be positively related to self-reported PSRB.

\section{Counterproductive work behaviors and discriminant validity}

Due to its pro-social motivations, Morrison (2006) emphasized that PSRB is conceptually distinct from traditional forms of deviance and misbehavior that are conducted primarily out of self-interest or a desire to harm the organization or its members. These destructive forms of deviance are oftentimes described as counter-productive work behaviors (CWB; Gruys \& Sackett, 2003; Robinson \& Bennett, 1995). Common forms of CWB include behaviors such as wasting time, gossiping, physical or verbal violence, and theft, which are motivated by instrumental or vindictive concerns (Vardi \& Weitz, 2004). In contrast, PSRB is motivated by honorable intentions to meet normative expectations, and therefore PSRB and other forms of constructive deviance are theoretically distinct from CWB and destructive deviance. However, as Galperin (2005) noted, both PSRB and CWB share a common willingness to volitionally deviate from the established rules of the organization, and they may consequently be 
positively related. We submit that CWB and PSRB will exhibit a positive relationship consistent with Galperin's (2005) reasoning, yet will remain empirically and conceptually distinct from each other.

Hypothesis 4: CWB will have a positive relationship with PSRB, yet will remain empirically distinct.

\section{Performance and criterion-related validity}

We focused on predicting supervisor ratings of task performance in Study 2 to provide initial evidence of the criterion-related validity of our measure of PSRB. However, the expected direction of the relationship between

PSRB and performance ratings is ambiguous. Contradictory evidence suggests that PSRB might contribute to, or detract from, performance ratings. From one perspective, Morrison (2006) suggested that PSRB should enhance performance. For example, in her Study 2, she asked participants to provide examples of PSRB and to explain the underlying rationale that motivated this behavior. Many of the rationales reported by participants involved satisfying aspects of task performance, such as meeting production objectives, completing projects, saving time and money for the organization, taking care of subordinates who required assistance, and building good relationships with clients and customers. These findings fit well with the conceptual orientation of PSRB; this is a form of behavior motivated by constructive intentions and designed to help the organization, so some existing data suggests that supervisors should be receptive to these rule violations because they lead to positive, task-related outcomes.

In contrast, there is a conflicting literature that suggests that observers might react poorly to PSRB. For example, supervisors establish rules and policies as controlling mechanisms that are designed to guide the behavior of employees, and most organizational functions and reward systems operate under the assumption that following these rules is necessary for effective performance (March, Schulz, \& Zhou, 2000). Rotundo and Sackett (2002) provided support for this notion by demonstrating that raters weigh counterproductive deviance when generating global performance evaluations. PSRB has a constructive motive, unlike counterproductive deviance, which is driven by selfish or destructive concerns. However, other stakeholders might not recognize these differences and may negatively evaluate both PSRB and counterproductive deviance as similar examples of rule breaking. Because the literature suggests that PSRB could either be positively or negatively related to task performance ratings, we approached this relationship as an exploratory question:

Exploratory Question: What is the relationship between PSRB and performance ratings?

In summary, we expect that PSRB will be negatively related to conscientiousness, positively related to both perceptions of job demands and PSRB performed by others, and positively related to, yet distinct from, counterproductive deviance. We will test and evaluate the relationship between PSRB and ratings of task performance on an exploratory basis.

\section{Method}

\section{Procedure}

The participants in this study completed a self-report survey for course credit in small group settings. To complete the study, each participant was also given a survey for their supervisor to collect performance ratings. The supervisor survey was returned to the researchers through the mail; both the subordinate and supervisor were blind to each other's responses.

\section{Sample}

Our sample consisted of 211 employed students from a small college in the Northeastern United States. The mean age of the sample was 21.3 and respondents were 71.6 per cent female. Further, the sample was 80.5 per cent Caucasian, 10.5 per cent African American, 5.2 per cent Hispanic, 0.5 per cent Asian American, and 3.3 per cent 
identified as "Other." We screened participants to only include respondents who were employed in jobs with the opportunity to interact with both coworkers and customers or clients. The sample worked an average of 21.1 hours per week with a mean tenure of 26.4 months. The response rate from supervisors to their follow-up survey was 100 per cent.

\section{Measures}

The measures used in the self-report and supervisor surveys are reported below. Unless otherwise indicated, all responses were on five-point scales ranging from 1: strongly disagree to 5: strongly agree.

PSRB was measured using the 13-item scale derived in Study 1 and shown in Table 1. For this study, $\alpha=0.89$ for the efficiency subscale, 0.92 for the coworker assistance subscale, 0.93 for the customer service subscale, and 0.95 for the overall scale.

Conscientiousness was measured using the eight-item conscientiousness subscale from Saucier's (1994) "minimarker" self-report scale $(\alpha=0.87)$. Participants were asked to indicate the extent to which each trait item described them. Sample items include "organized" and "careless."

Perceived job demands were measured with the job demands items from Karasek's (1979) Job Demands and Decision Latitude measure. A sample item reads, "To what extent does your job require a great deal of work to be done?" Responses to the seven items $(\alpha=0.84)$ were measured with anchors ranging from "not at all" to "to a large extent."

Perceptions of PSRB performed by others were measured with a six-item scale ( $\alpha=0.93$ ) developed for this study. Sample items include "People in my organization sometimes break the company's rules if it means that the company will benefit," and "Members of my organization sometimes find it necessary to break the company's rules in order to provide good customer service."

Counterproductive work behaviors were measured with Fox and Spector's (1999) Adapted Job Reactions Survey. This measure has four subscales: an 11-item measure of minor CWBs directed toward the organization $(\alpha=0.84)$, a six-item measure of minor CWBs directed toward coworkers $(\alpha=0.68)$, a five-item measure of major CWBs directed toward the organization $(\alpha=0.73)$, and a five-item measure of major CWBs directed toward coworkers $(\alpha=0.77)$. A sample item from the minor, organizational CWB subscale reads, "Purposefully wasted company materials/supplies," and a sample item from the major, coworker CWB subscale reads, "Started an argument with someone at work." Responses were on a five-point scale ranging from "never" to "extremely often." The internal consistency of the overall scale was $\alpha=0.89$.

Task performance was measured with Williams and Anderson's (1991) scale. A sample item from the seven-item $(\alpha=0.80)$ task performance scale is, "Adequately completes assigned duties."

\section{Results}

\section{CFA}

We conducted a series of CFAs using MPLUS version 4.21 (Muthén \& Muthén, 1998-2007) to confirm the factor structure for the GPSRBS found in Study 1 and to test our hypotheses. We started by confirming the factor structure of the GPSRBS and found that the hypothesized, three-factor model fit the data very well $\left(\chi^{2}(62)=117.59, p<0.01\right.$; $\mathrm{CFI}=0.98 ; \mathrm{TLI}=0.97 ; \mathrm{RMSEA}=0.07 ; \mathrm{SRMR}=0.04)$. We then tested an alternative model that fixed all $13 \mathrm{PSRB}$ items on one general PSRB factor, which showed considerably worse fit to the data $\left(\chi^{2}(65)=545.97, p<0.01\right.$; $\mathrm{CFI}=0.79 ; \mathrm{TLI}=0.75 ; \mathrm{RMSEA}=0.19 ; \mathrm{SRMR}=0.08$ ). The results of this analysis indicate that the factor structure found in Study 1 fits the data well in a confirmatory framework with a second sample, indicating that the factor structure of the measure is stable. However, we did observe that the three factors of the GPSRBS exhibited strong relationships in the hypothesized model, with latent variable correlations ranging from 0.72 to 0.80 . Consequently, we modeled a higher-order PSRB construct as shown in Figure 1. We test our hypotheses in the analyses that follow with respect to this higher-order PSRB construct. 


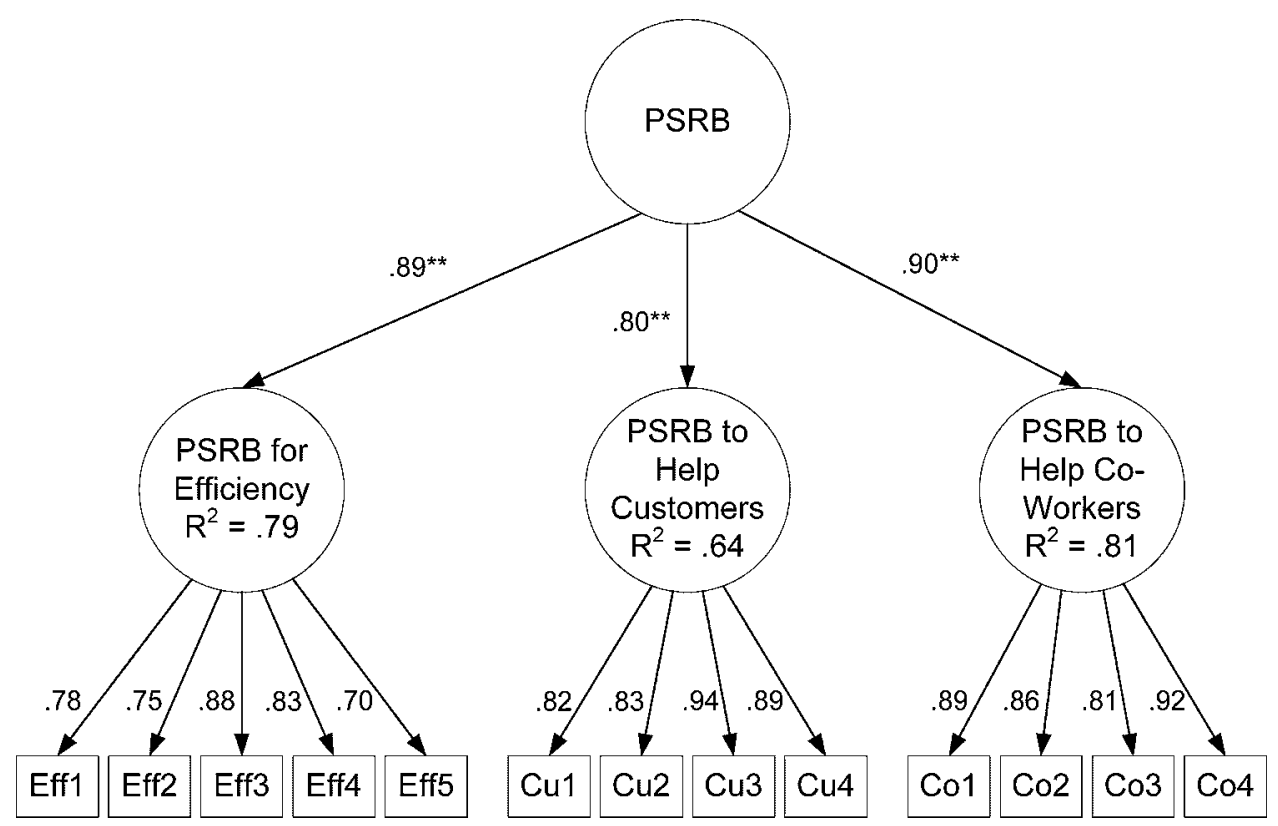

Figure 1. Confirmatory factor analysis of GPSRBS, Study 2

\section{Tests of hypotheses}

Table 3 presents the means, standard deviations, and correlations for the manifest scale scores of the variables measured in Study 2. We tested Hypotheses 1-4 by specifying a measurement model that included all six constructs (PSRB, conscientiousness, job demands, perceptions of PSRB performed by others, CWB, and task performance ratings) and evaluating the latent variable correlations. Consistent with Figure 1, the PSRB construct was indicated by the scale scores for the three dimensions. The CWB construct was indicated by the scale scores of its own four dimensions, and the remaining uni-dimensional constructs were indicated by their individual items. Overall, this measurement model fit the data reasonably well $\left(\chi^{2}(512)=1179.96, p<0.01 ; \quad C F I=0.88 ; \quad\right.$ TLI $=0.85$; RMSEA $=0.08 ;$ SRMR $=0.07$ ).

With respect to the latent variable correlations, we found support for most of our hypotheses. Conscientiousness was negatively related to PSRB consistent with Hypothesis $1(r=-0.30, p<0.01)$. However, no support was found for Hypothesis 2; the relationship between job demands and PSRB was not statistically significant in a SEM framework $(r=0.15, p=0.08)$, although the correlation between the manifest scale scores was significant and in the expected direction $(r=0.14, p<0.05)$. Hypothesis 3, which stated that perceptions of PSRB performed by others would be positively related to self-reported PSRB, was supported $(r=0.59, p<0.01)$.

Hypothesis 4 stated that PSRB would have a positive relationship with CWB, yet would remain empirically distinct. We found a positive correlation between the latent constructs in support of this hypothesis $(r=0.54$, $p<0.01$ ), which we expected because both PSRB and CWB involve a willingness to deviate from rules and norms despite their different underlying intentions. However, the magnitude of the relationship is not strong enough to suggest that PSRB and CWB are not distinct constructs.

We conducted a supplementary analysis using a method proposed by Bagozzi, Yi, and Phillips (1991) to more formally demonstrate that CWB is distinct from PSRB. This procedure uses structural equation modeling to compare two nested models. First, we specified a structural model that constrained the covariance between PSRB and CWB to one, which treats them as the same, unitary construct $\left(\chi^{2}(702)=2319.93, p<0.01\right)$. Second, we specified a nested structural model that allowed PSRB and CWB to freely co-vary as distinct constructs $\left(\chi^{2}(701)=2283.90, p<0.01\right)$. 


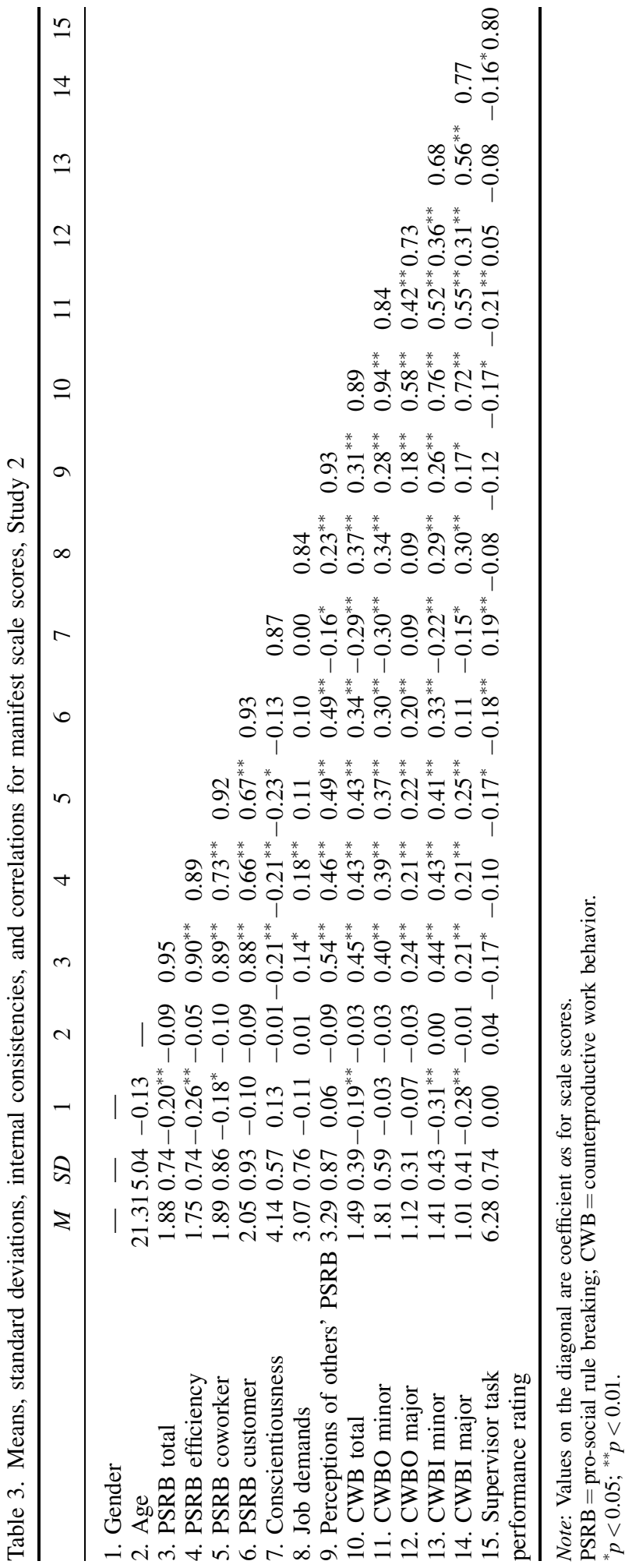


According to Bagozzi et al. (1991), if the constructs are distinct from each other, the second model in which the constructs are allowed to freely co-vary will demonstrate better fit to the data than the first model in which the constructs are held to be unitary. Consistent with our expectations, the results indicate that the model in which PSRB and CWB are allowed to freely co-vary fits the data significantly better than the model in which the constructs are forced to be unitary $\left(\Delta \chi^{2}(1)=36.03, p<0.01\right)$. Thus, our tests of Hypothesis 4 indicate that PSRB and CWB are positively related, yet separate constructs.

Lastly, we posed an exploratory question concerning the relationship between PSRB and performance due to conflicting evidence that suggested that PSRB could either enhance or detract from performance ratings. We found that the PSRB construct was negatively related to task performance ratings provided by supervisors $(r=-0.17$, $p<0.05)$. An examination of the manifest GPSRBS subscale correlations in Table 3 indicates that task performance is negatively related to both the coworker assistance $(r=-0.17, p<0.05)$ and customer assistance $(r=-0.18$, $p<0.05$ ) forms of PSRB. The efficiency form of PSRB was not significantly related to performance, although this relationship also trended in a negative direction $(r=-0.10, p=0.14)$.

\section{Discussion}

Overall, the results in Study 2 were consistent with our expectations. We found additional evidence for the reliability and factorial stability of the GPSRBS. In addition, we found that conscientiousness and perceptions of PSRB performed by others were both predictive of PSRB. In particular, perceptions of others' PSRB had a strong, positive relationship with PSRB. This finding converges nicely with Morrison's (2006) research, which found that manipulating her PSRB vignette to indicate that others had broken a rule before resulted in greater willingness to engage in PSRB. Further, it is consistent with related research that indicates that destructive deviance committed by coworkers can contribute to increases in self-reported destructive deviance (e.g., Robinson \& O'Leary-Kelly, 1998).

We also demonstrated that PSRB as measured by our scale is distinct from CWB. The constructs are significantly and positively correlated, which we expected based on the shared willingness to break rules that underlies both constructs. However, the relationship is not strong enough to question the distinctiveness of PSRB from CWB, and we rejected an alternative model that explicitly tested whether or not the PSRB and CWB items are indicators of a single unitary construct.

The results of our exploratory question concerning PSRB and supervisor ratings of task performance suggest that supervisors evaluate PSRB negatively. This pattern of results is consistent with the reasoning that supervisors, as rule enforcers (March et al., 2000), are likely to respond negatively to even well-intentioned forms of rule-breaking behavior. Some further support for this idea is evident in Mayer et al.'s (2007) finding that PSRB is more likely when the supervisor-subordinate relationship is positive, implying that subordinates are concerned about managerial backing when considering PSRB. However, we reasoned that other organizational stakeholders without the responsibility for setting and enforcing rules, such as coworkers, might react differently to PSRB. Further, we considered that PSRB might exhibit different relationships with other forms of performance, such as organizational citizenship behaviors (OCBs; Podsakoff, MacKenzie, Moorman, \& Fetter, 1990). Consequently, we conducted a third study to place the GPSRBS in a broader network of performance criteria and stakeholder perspectives.

\section{Study 3: Further Criterion-Validity Evidence}

Study 3 had several objectives. Most importantly, we sought to expand on the evaluation of our Exploratory Question concerning the relationship between PSRB and performance. We accomplished this by (a) incorporating the perspective of both coworkers and supervisors of employees who commit PSRB, and (b) collecting these 
stakeholders' ratings of task performance, OCBs directed toward individuals (OCBIs), and CWB to place PSRB in a broader criterion network. We also addressed a few potential methodological limitations from Study 2. Specifically, we attempted to sample participants from a wider variety of organizations and we elected to use different measures of performance and CWB in this study to eliminate the possibility that our criterion-related findings in Study 2 were due to the particular scale we employed (Lykken, 1968). Finally, Study 3 allowed us to re-confirm that the factor structure of the GPSRBS measure is stable and reliable using a new sample of part-time and full-time employees.

OCBIs refer to extra-role behaviors designed to directly help or benefit specific people with whom one works, which should indirectly benefit the organization (Williams \& Anderson, 1991). We incorporated OCBIs into a broader evaluation of our Exploratory Question concerning performance for several reasons. First, like PSRB, OCBs are constructively motivated and involve some level of deviation from the norm of what is typically expected or rewarded (Organ, 1988). Second, two of the three types of PSRB that Morrison (2006) identified were interpersonal in nature (i.e., customer-oriented and coworker-oriented). Consequently, it might be the case that PSRB is more closely associated with OCBIs than traditional task performance. We therefore asked both supervisors and coworkers to also rate OCBIs directed toward peer coworkers and toward customers.

\section{Method}

\section{Procedure}

We recruited participants using a snowball sampling procedure (e.g., Grant \& Mayer, 2009; Morgeson \& Humphrey, 2006; Skarlicki \& Folger, 1997). We sent an electronic message to 232 undergraduate business major students and provided them with the opportunity to help with a study for extra credit. Students who worked at least 20 hours per week were allowed to participate in the study; if they did not satisfy this employment requirement, they were asked to invite a family member or close other to participate instead. Focal respondents were instructed to visit a website to complete a survey and to send separate electronic survey links to their supervisor and a coworker familiar with their work. All respondents were assured that their responses would remain confidential. For this study, the focal employee completed a self-report measure of PSRB. The supervisor and coworker each provided ratings of the focal employee's task performance, two forms of OCBI (helping coworkers and helping customers), and two forms of CWB (organizationally directed and interpersonally directed).

\section{Sample}

The sample consisted of 109 matched triads (a 47 per cent response rate). Focal respondents were recruited from a large university in the Southeastern United States. The mean age of focal respondents was 23.8 years old with a mean tenure of 24.5 months in their current jobs. Part-time employees constituted 70 per cent of the sample. The sample was 49.3 per cent female and 65 per cent Caucasian, 7.9 per cent Hispanic, 5.7 per cent Asian American, 5 per cent Latino/a, and 4.3 per cent African American.

The sample of matched coworkers was 60 per cent male with a mean of 29.3 years of age and 4.2 years of tenure with their current organization. This sample was 68 per cent Caucasian, 8 per cent Hispanic, 8 per cent Latino/a, 7 per cent Asian American, 6 per cent African-American, 2 per cent biracial, and 1 per cent of another racial background. Sixty-eight per cent of the coworker sample worked part-time.

The matched supervisor sample was 53 per cent male with a mean 37.1 years of age and 8.5 years of tenure with the organization. Ninety-seven per cent of the supervisors worked full-time. This sample was 75 per cent Caucasian, 10 per cent Hispanic, 6 per cent African American, 3 per cent Asian American, 2 per cent Latino/a, 1 per cent Native American, and 3 per cent of another racial background.

Measures: PSRB was self-reported by focal respondents using the 13-item scale developed in Study 1 . The internal consistency of the overall scale for this study was $\alpha=0.97$. For the sub-scales, efficiency $\alpha=0.95$, coworker assistance $\alpha=0.95$, and customer assistance $\alpha=0.96$. 
Both supervisors and coworkers rated the task performance, OCBIs, and CWB exhibited by the focal respondent. All rater responses were on a seven-point scale where $1=$ strongly disagree and $7=$ strongly agree.

Task performance was evaluated by both raters using a six-item measure ( $\alpha=0.94$ for supervisors and 0.96 for coworkers) developed by Alper, Tjosvold, and Law (2000). Sample items from this scale read, "Meets or exceeds his/her productivity requirements" and "Is committed to producing quality work."

OCBIs were measured using two scales. First, we used a five-item measure pertaining to extra-role helping of coworkers (Podsakoff et al., 1990; $\alpha=0.93$ for both the supervisors and coworkers). A sample item from this scale reads, "Helps others who have heavy workloads." The second scale pertained to extra-role helping of customers (Bettencourt \& Brown, 1997; $\alpha=0.97$ for the supervisors and 0.93 for coworkers). A sample item from this scale is, "Helps customers with problems beyond what is expected or required."

CWB was measured with Robinson and Bennett's (1995) measure, which includes seven items intended to measure interpersonal CWB and 12 items intended to measure organizational CWB (overall $\alpha=0.93$ for supervisors and 0.96 for coworkers). A sample item from the interpersonal subscale reads, "Acted rudely toward people at work," whereas a sample item from the organizational subscale reads, "Puts little effort into his/her work."

\section{Results}

\section{CFA}

We again started by confirming the factor structure of the GPSRBS. Fit indices for the measurement model indicate that the hypothesized model fit the data adequately $\left(\chi^{2}(62)=177.99, p<0.01 ; \mathrm{CFI}=0.95 ; \mathrm{TLI}=0.94\right.$; $\mathrm{RMSEA}=0.12 ; \mathrm{SRMR}=0.03$ ), providing further evidence that the factor structure of the measure is stable across multiple samples.

\section{Hypothesis tests}

Table 4 shows the means, standard deviations, and correlations for the manifest scale scores, including the relationships between the individual PSRB, CWB, and OCB dimensions. Similar to Study 2, we evaluated the Exploratory Question by specifying an overall measurement model and evaluating the latent variable correlations. The PSRB latent construct was again indicated by the scale scores for its three dimensions. Two OCBI constructs were modeled, one as rated by the supervisor and one as rated by the coworker, and each construct was indicated by the respective scale scores for the OCB-customer and OCB-coworker scale scores. We followed the same practice to create two CWB constructs, which were indicated by the organizationally and interpersonally directed scale scores reported by each source. Lastly, we formed two task performance constructs that were indicated by the individual items as rated by each source, respectively.

Overall, this measurement model demonstrated adequate fit to the data $\left(\chi^{2}(209)=435.56, p<0.01 ; \mathrm{CFI}=0.89\right.$; $\mathrm{TLI}=0.87 ; \mathrm{RMSEA}=0.10 ; \mathrm{SRMR}=0.05$ ). With respect to task performance, we found latent variable correlations that were generally consistent with those found in Study 2. Self-reported PSRB was negatively related to coworker ratings of task performance $(r=-0.23, p<0.05)$. PSRB was not significantly related to supervisor ratings of task performance, but the relationship again trended in a negative direction $(r=-0.15, p=0.17)$. We found that PSRB was positively related to CWB as rated by coworkers $(r=0.23, p<0.05)$, but was unrelated to CWB as rated by supervisors. Lastly, the results indicated that PSRB was unrelated to OCBIs as rated by either the supervisor or the coworker.

To summarize our findings concerning our Exploratory Question across Study 2 and 3, PSRB exhibits (a) weak, negative relationships with supervisor and coworker task performance ratings, (b) positive relationships with coworker and self-ratings of CWB, and (c) no relationship with either supervisor or coworker ratings of OCBIs. Further, the magnitude of these relationships clearly indicates that PSRB is distinct from all of these other performance-related criteria. Interestingly, an examination of the dimension correlations in Table 4 shows that the negative relationship between overall PSRB and coworker ratings of task performance seems to be driven by 


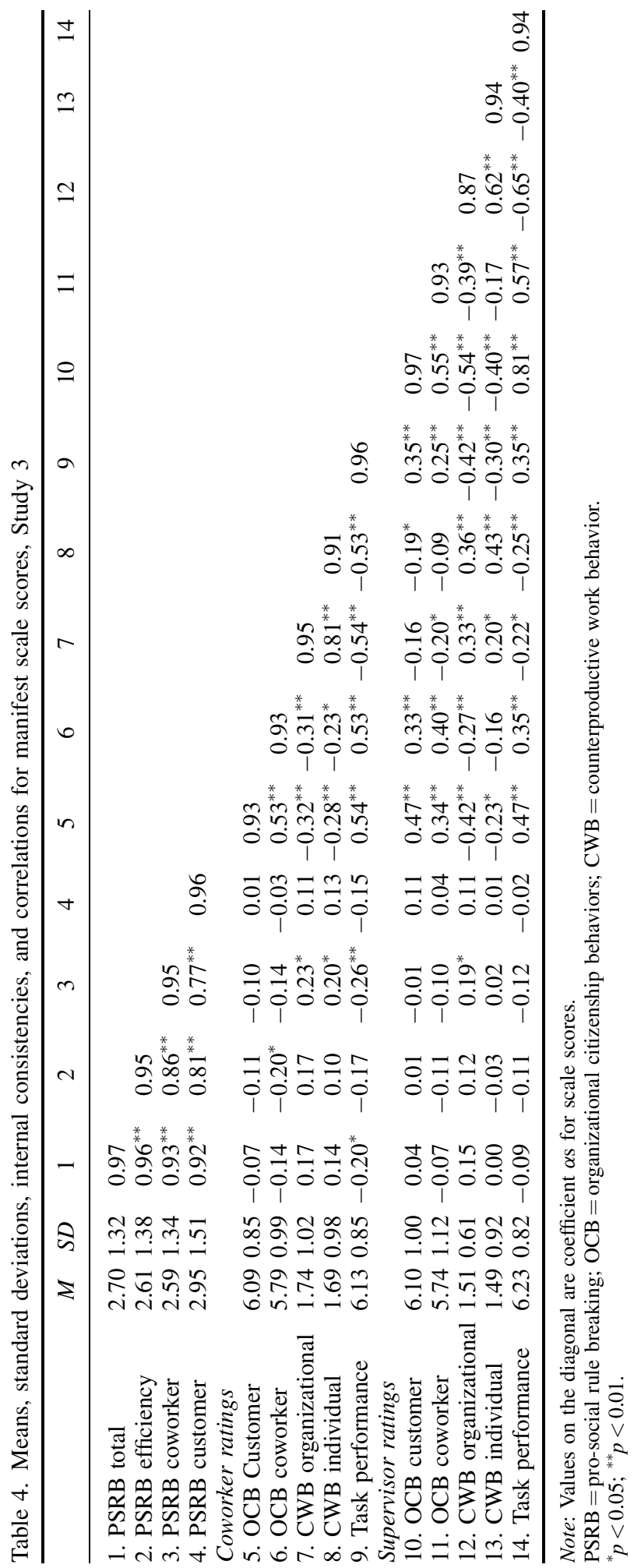

Copyright (C) 2010 John Wiley \& Sons, Ltd. 
coworker-directed PSRB. Thus, the results of Study 3 indicate that coworkers without a responsibility for rule enforcement also respond negatively to PSRB, like supervisors, even if the PSRB is intended to help those coworkers. We explore reasons why such constructively motivated behaviors may be appraised negatively below.

\section{General Discussion}

The overarching purpose of this paper was to develop a valid measure of PSRB that could be used in any organizational context. To this end, we collected a considerable amount of information that indicates that our scale satisfies the conditions necessary for construct validity. First, we demonstrated across all three studies that the GPSRBS is reliable, with coefficient $\alpha$ s for the subscales ranging from 0.86 to 0.96 . Second, the measures demonstrated content validity through (a) our initial sorting exercise with subject matter experts and (b) the stable factor structure that we found in Study 1 and replicated in Studies 2 and 3. Third, the GPSRBS is distinct from counterproductive work behaviors as shown in Studies 2 and 3, indicating that we are measuring a construct distinct from traditional notions of destructive deviance. Fourth, our measure demonstrated a pattern of negative relationships with performance ratings from both supervisors and coworkers, providing initial evidence of criterionrelated validity. Lastly, we placed our measure in a nomological network with several antecedents drawn from Vardi and Weitz's (2004) framework of OMB in Study 2 (i.e., conscientiousness, job demands, and perceptions of PSRB performed by others). In sum, all of our existing evidence suggests that the GPSRBS is a construct-valid measure of PSRB that can be used in a wide variety of organizational contexts.

Our results advance the study of constructive deviance in several respects. First, despite a considerable body of theoretical research on specific forms of positive or constructive deviance, very little empirical research has tested the many propositions that have been advanced about this family of behaviors (e.g., Galperin, 2003; Spreitzer \& Sonenshein, 2004; Vardi \& Wiener, 1996; Warren, 2003; Worline \& Quinn, 2003). We expect that our development and validation of a measure of PSRB that can be used in a variety of organizational settings will contribute to more research on this topic. Further, although clear theoretical differences have been drawn between destructive and constructive deviance (e.g., Applebaum, Iaconi, \& Matousek, 2007), this study makes an important contribution by empirically showing that PSRB is distinct from counterproductive work behaviors. Thus, although both constructive and destructive behaviors are similar in terms of their shared emphasis on deviating from rules and norms, we demonstrated that respondents draw a distinction between deviance committed with constructive and destructive intentions.

\section{Implications for research and practice}

Perhaps the most important implication for future research and practice raised by our findings is the relationship between PSRB and performance criteria. We initially approached the relationship between PSRB and task performance ratings as an exploratory question by presenting evidence that the relationship could be either positive or negative. The results of Study 2 indicated that supervisors reacted negatively to PSRB, which we reasoned was due to the responsibility that supervisors hold for setting and enforcing rules. However, we found in Study 3 that coworkers also rated task performance lower for those employees who reported more PSRB. Further, PSRB was unrelated to ratings of OCBIs made by both supervisors and coworkers. These convergent findings suggest that it is not merely a responsibility for rule enforcement that is driving the PSRB-performance relationship. Rather, there seem to be more complicated processes underlying rater reactions to constructive deviance.

We see several potential explanations for the negative performance ratings reported by both supervisors and coworkers, each of which is an important, testable direction for future research. We feel that the most likely 
explanation concerns the erroneous dispositional inferences that raters are likely to draw about constructive rule breakers. Research on the correspondence bias (Gawronski, 2004; Gilbert \& Malone, 1995; Jones, 1990) indicates that perceivers tend to draw correspondent dispositional inferences based on the behavior of others, even when situational factors are genuinely responsible for the behavior (Kunda, 2000). For example, consider again the hypothetical situation in which a waiter chooses to calm down an angry customer by violating organizational rules and giving the customer a free dessert. From the waiter's perspective, the choice to break organizational rules is situationally determined - the customer is upset and retaining his business is important to the organization, so in these constrained circumstances, PSRB is a rational, appropriate response that generates the best possible outcome for the organization. However, from the perspective of an observing rater, such as a supervisor or coworker, the influence of the situation on the waiter's rule-breaking decision is underestimated. Rather, the rater attributes the choice to break rules to the disposition of the waiter, who may be subsequently perceived as reckless, low in conscientiousness, or not respectful of the organization because he broke rules - from the rater's perspective-for no good reason. We suggest that these negative dispositional attributions may be responsible for the negative relationship between PSRB and ratings of task performance. Future research could test this idea by examining dispositional attributions as mediators of the PSRB-performance rating relationship.

Another theoretically plausible explanation for this negative relationship is that PSRB may give rise to destructive deviance over time. Support for this idea is evident in the literature on ethical fading, which is a process wherein the ethical implications of behaviors fade into the background, allowing the individual to engage in unethical behavior without becoming consciously aware of it (Gino \& Bazerman, 2009; Tenbrunsel \& Messick, 2004). A variety of processes, such as psychic numbing (Bok, 1989) and moral disengagement (Bandura, 1999), have been proposed as mechanisms that facilitate ethical fading, allowing well-intentioned rule breaking to evolve into destructive rule breaking with negative consequences for the organization and the employee. Following Tenbrunsel and Messick's (2004) theory, repetitive, constructive rule breaking can desensitize employees to the ethical concerns surrounding violating organizational rules in general and introduce a sense of routine into rule breaking behavior. Concurrently, the domain of acceptable rule breaking behavior widens and begins to include behaviors that are increasingly selfinterested and dysfunctional for the organization. However, rather than realizing that these behaviors are no longer pro-social, employees would continue to evaluate them as constructively motivated, desirable, and even necessary to continue providing effective job performance.

Consequently, a second explanation for the negative relationship between PSRB and performance ratings is that supervisors and coworkers are both aware that constructive rule-breaking behavior, if condoned, can open the door for counterproductive deviance later. This explanation assumes that raters do accurately appraise PSRB as a constructive form of deviance, but that they see even constructive deviance as too risky to tolerate from a long-term perspective. An important direction for future research would be to examine PSRB in a longitudinal study to see if PSRB early in an employee's tenure is predictive of counterproductive deviance and performance ratings in the future. We expect that counterproductive deviance would mediate the relationship between PSRB and performance ratings in a longitudinal study if ethical fading were the mechanism driving the negative relationship between PSRB and task performance.

Third, the relationship between PSRB and performance ratings may be negative because PSRB is categorized as "pro-social" only in hindsight by the rule breaker. Thus, it is possible that the negative performance rating provided by supervisors and coworkers represents an accurate evaluation of self-interested deviance that the focal respondent is rationalizing in a positive light. A number of well-known implicit biases may have a bearing on why employees would characterize their self-interested deviance as pro-social, particularly in terms of conflicts of interest as described by Bazerman et al. (Banaji, Bazerman, \& Chugh, 2004; Bazerman \& Banaji, 2004; Bazerman, Chugh, \& Banaji, 2005). Conflicts of interest exist when employees are forced to choose between behaviors that benefit the organization versus behaviors that benefit themselves. Bazerman and colleagues have conducted research on managers, accountants, and brokerage analysts that indicates that people frequently fail to detect the influence that conflicts of interest have on their decision-making processes. These conflicts are overlooked largely because people operate within a framework of bounded ethicality (Bazerman \& Chugh, 2006; Chugh, Banaji, \& Bazerman, 2005), 
meaning that their decisions are constrained by their own self-view as decent, moral, and competent individuals. Consequently, because people operate under the assumption that they are consistently moral and correct in their decisions, many unethical choices are reframed as sound, or even self-sacrificing (Chugh et al., 2005). Bearing in mind Morrison's (2006) suggestion that PSRB can be motivated by mixed motives as long as the primary motive is pro-social, we find it possible that self-interested behavior could easily be sanitized and mentally re-categorized as pro-social in the same fashion described by Chugh et al. (2005), allowing a process of self-deception to unfold.

Lastly, we suggest that organizational culture and climates may play a role in determining which forms of PSRB are seen as acceptable or unacceptable by other organization members. For example, customer-oriented PSRB may not be perceived negatively in an organization with a strong customer service climate (Schneider, White, \& Paul, 1998). In such a climate, honoring the higher-order value of providing excellent service may be perceived as more important than complying with a procedural rule about customer interactions. On the other hand, PSRB to improve efficiency may be seen as particularly risky and intolerable in an organization that has a strong safety climate (Hofmann \& Stetzer, 1996) in which rule abidance is seen as critical to preserving the safety and well-being of all employees. Future research should examine the potential moderating effects of culture and climate on the relationship between PSRB and performance ratings.

\section{Limitations}

Several limitations of our studies should be noted. First, many of the measures we collected were self-reported, and this approach may artificially inflate some of the relationships we found. For example, the strong correlation observed in Study 2 between self-reported PSRB and perceptions of PSRB performed by others may be attributable to the fact that the focal respondent provided data for both variables. Future research can explore this relationship in greater detail by collecting reports of PSRB from groups or teams of employees and aggregating the data to examine how group-level PSRB influences individual PSRB (Robinson \& O'Leary-Kelly, 1998).

A second limitation concerns the samples we employed. Although we sought to draw participants from a variety of organizations in Studies 2 and 3, our samples still consisted predominately of female students in their early-to-mid 20s. Most of these participants were in lower-level service positions that are oftentimes characterized by low autonomy (Korczynski, 2002). Disciplinary responses to rule-breaking behavior, even if pro-socially motivated, may be more severe in these types of jobs than in higher-level or managerial positions that are distinguished by more autonomy and a greater expectation for flexibility or adaptability. Further, lower-level employees may lack the accumulated idiosyncrasy credits to deviate from rules and remain liked, trusted, and accepted in their workgroups (Stone \& Cooper, 2009). Future research could examine the consequences of PSRB in a more diverse sample consisting of participants from different levels of organizational hierarchies to test these ideas.

Third, the measure of conscientiousness that we used emphasized the aspects of conscientiousness that have to do with dutifulness and orderliness. In contrast, facet-level research indicates that high conscientiousness also involves a propensity toward achievement striving (Costa \& McCrae, 1992). The achievement-striving facet may exhibit a different relationship with PSRB, particularly PSRB to improve efficiency, relative to the dutifulness and orderliness facets. Future research should explore these possibilities.

Fourth, our measure does contain strong language; we refer directly to "violating" and "breaking" rules or policies. Although we do also include softer euphemisms like "disregarding" and "bending" in some items, we do acknowledge that this language may give rise to socially desirable responses. However, we suggest that employees who are breaking rules for pro-social reasons would see little reason to adjust their responses downward. From their perspective, the rule-breaking behavior is justified and in the collective good, and consequently it should not elicit self-consciousness or concern about negative stigmatization.

A final point to acknowledge is that our decision to create a generalizable measure of PSRB means that we sacrificed our ability to measure idiosyncratic examples of PSRB within any specific organization. For example, coworker-focused PSRB might manifest as many different types of behaviors depending on the nature of the tasks 
that the respondent and coworker are expected to perform in a given job and organization. However, the GPSRBS does not capture these differences. Our scale would need to be modified if researchers have specific expectations about the antecedents or consequences of narrowly defined examples of PSRB within a particular work context.

\section{Conclusion}

The results of this research indicate that the GPSRBS has the potential to facilitate further research on the constructive choices that employees make when they break rules in response to organizational demands. As is the case with any new scale, we recognize the need for further validation of the GPSRBS and hope that future researchers explore its usefulness to study this important form of organizational behavior.

\section{Acknowledgements}

The authors thank Francesca Gino for her help in the development of this article.

\section{Author biographies}

Jason Dahling is an assistant professor in the Psychology Department at The College of New Jersey. His consulting and research interests include performance appraisal and feedback, emotional labor in customer service settings, and employee deviance from organizational rules.

Samantha Chau is a Sr. Specialist in Talent Management at Novo Nordisk Inc. She received her PhD in Industrial/ Organizational Psychology from the University of Akron. She is also an adjunct faculty member at The College of New Jersey. Her applied and research interests include emotional labor, feedback dynamics, and employee selection and performance.

David Mayer is an assistant professor in the Management \& Organizations Department in the Ross School of Business at the University of Michigan. His research interests concern social and ethical issues in organizations and focus primarily on behavioral ethics, organizational justice, and workplace diversity.

Jane Brodie Gregory is a manager of leadership development at Procter and Gamble. She received her PhD in Industrial/Organizational Psychology from The University of Akron. Her research focuses largely on coaching, feedback, development, and performance management.

\section{References}

Alper, S., Tjosvold, D., \& Law, K. S. (2000). Conflict management, efficacy, and performance in organizational teams. Personnel Psychology, 53, 625-642.

Applebaum, S. H., Iaconi, G. D., \& Matousek, A. (2007). Positive and negative deviant workplace behaviors: Causes, impacts, and solutions. Corporate Governance: The International Journal of Business in Society, 7, 586-598. 
Ashford, S. J., Rothbard, N. P., Piderit, S. K., \& Dutton, J. E. (1998). Out on a limb: The role of context and impression management in selling gender-equality issues. Administrative Science Quarterly, 43, 23-57.

Ashton, M. C. (1998). Personality and job performance: The importance of narrow traits. Journal of Organizational Behavior, 19, 289-304.

Bagozzi, R. P., Yi, Y., \& Phillips, L. W. (1991). Assessing construct validity in organizational research. Administrative Science Quarterly, 36, 421-458.

Banaji, M. R., Bazerman, M. H., \& Chugh, D. (2004). How (un)ethical are you? Harvard Business Review, 82, 56-64.

Bandura, A. (1999). Moral disengagement in the perpetuation of inhumanities. Personality and Social Psychology Review, 3, 193-209.

Barrick, M. R., \& Mount, M. K. (1991). The Big Five personality dimensions and job performance: A meta-analysis. Personnel Psychology, 44, 1-26.

Bazerman, M. H., \& Banaji, M. R. (2004). The social psychology of ordinary ethical failures. Social Justice Research, 17, 111115.

Bazerman, M. H., \& Chugh, D. (2006). Decisions without blinders. Harvard Business Review, 84, 88-97.

Bazerman, M. H., Chugh, D., \& Banaji, M. R. (2005). When good people (seem to) negotiate in bad faith. Negotiation, 8, 1-4.

Bettencourt, L. A., \& Brown, S. W. (1997). Contact employees: Relationships among workplace fairness, job satisfaction and prosocial service behaviors. Journal of Retailing, 73, 39-61.

Bok, S. (1989). Secrets. New York, NY: Vintage Books.

Brief, A. P., \& Motowidlo, S. J. (1986). Prosocial organizational behaviors. Academy of Management Review, 11, $710-725$.

Chung, B. G., \& Schneider, B. (2002). Serving multiple masters: Role conflict experienced by service employees. Journal of Services Marketing, 16, 70-85.

Chugh, D., Banaji, M. R., \& Bazerman, M. H. (2005). Bounded ethicality as a psychological barrier to recognizing conflicts of interest. In D. Moore, D. Cain, G. Loewenstein, \& M. Bazerman (Eds.), Conflicts of interest: Problems and solutions from law, medicine, and organizational settings. London: Cambridge University Press.

Comrey, A. L., \& Lee, H. B. (1992). A first course in factor analysis (2nd ed.). Hillsdale, NJ: Lawrence Erlbaum Associates.

Costa, P. T., \& McCrae, R. R. (1992). Normal personality assessment in clinical practice: The NEO Personality Inventory. Psychological Assessment, 4, 5-13.

Cullen, M. J., \& Sackett, P. R. (2003). Personality and counterproductive work behavior. In M. Barrick, \& A. M. Ryan (Eds.), Personality and work (pp. 150-182). San Francisco, CA: Jossey-Bass.

Dutton, J. E., Ashford, S. J., O’Neill, R. M., Hayes, E., \& Wierba, E. E. (1997). Reading the wind: How middle managers assess the context for selling issues to top managers. Strategic Management Journal, 18, 407-423.

Fabrigar, L. R., Wegener, D. T., MacCallum, R. C., \& Strahan, E. J. (1999). Evaluating the use of exploratory factor analysis in psychological research. Psychological Methods, 4, 272-299.

Fishbein, M., \& Ajzen, I. (1975). Belief, attitude, intention and behavior: An introduction to theory research. Readings, MA: Addison-Wesley.

Fox, S., \& Spector, P. E. (1999). A model of work frustration-aggression. Journal of Organizational Behavior, $20,915-931$.

Galperin, B. L. (2003). Can workplace deviance be constructive? In A. Sagie, S. Stashevsky, \& M. Koslowsky (Eds.), Misbehavior and dysfunctional attitudes in organizations (pp. 154-170). New York, NY: Palgrave Macmillan.

Galperin, B. L. (2005). Examination of the moderating and mediating effect of role breadth self-efficacy in explaining deviance. In K. Mark Weaver, (Ed.), Proceedings of the Sixty-fifth Annual Meeting of the Academy of Management (CD), ISSN 1543-8643.

Gawronski, B. (2004). Theory-based bias correction in dispositional inference: The fundamental attribution error is dead, long live the correspondence bias. European Review of Social Psychology, 15, 183-217.

Gilbert, D. T., \& Malone, P. S. (1995). The correspondence bias. Psychological Bulletin, 117, 21-38.

Gino, F., \& Bazerman, M. H. (2009). When misconduct goes unnoticed: The acceptability of gradual erosion in others' unethical behavior. Journal of Experimental Social Psychology, 45, 708-719.

Gino, F., \& Pierce, L. (in press). Robin Hood under the hood: Wealth-based discrimination in illicit customer help. Organization Science. DOI: $10.1287 /$ orsc.1090.0498.

Grant, A. M. (2008). Does intrinsic motivation fuel the prosocial fire? Motivational synergy in predicting persistence, performance, and productivity. Journal of Applied Psychology, 93, 48-58.

Grant, A. M., \& Mayer, D. M. (2009). Good soldiers and good actors: Prosocial and impression management motives as interactive predictors of citizenship behavior. Journal of Applied Psychology, 94, 900-912.

Gruys, M. L., \& Sackett, P. R. (2003). Investigating the dimensionality of counterproductive work behavior. International Journal of Selection and Assessment, 11, 30-42.

Hinkin, T. R. (1995). A review of scale development practices in the study of organizations. Journal of Management, 21, 967-988. 
Hofmann, D. A., \& Stetzer, A. (1996). A cross-level investigation of factors influencing unsafe behaviors and accidents. Personnel Psychology, 49, 307-339.

Hoyle, R. H., \& Duvall, J. L. (2004). Determining the number of factors in exploratory and confirmatory factor analysis. In D. Kaplan (Ed.), Handbook of quantitative methodology for the social sciences (pp. 301-315). Thousand Oaks, CA: Sage Publications.

Jones, E. E. (1990). Interpersonal perception. New York, NY: Freeman.

Jones, T. M. (1991). Ethical decision making by individuals in organizations: An issue-contingent model. Academy of Management Review, 16, 366-395.

Karasek, R. A. (1979). Job demands, job decision latitude, and mental strain: Implications for job redesign. Administrative Science Quarterly, 24, 285-308.

Korczynski, M. (2002). Human resource management in service work. Basingstroke, UK: Palgrave Macmillan.

Kunda, Z. (2000). Social cognition: Making sense of people. Cambridge, MA: MIT Press.

Levine, J. M., \& Moreland, R. L. (1998). Small groups. In D. T. Gilbert, S. T. Fiske, \& G. Lindzey (Eds.), The handbook of social psychology (4th ed., pp. 415-469). New York, NY: McGraw-Hill.

Little, T. D., Lindenberger, U., \& Nesselroade, J. R. (1999). On selecting indicators for multivariate measurement and modeling with latent variables: When "good" indicators are bad and "bad" indicators are good. Psychological Methods, 4, 192-211.

Lykken, D. T. (1968). Statistical significance in psychological research. Psychological Bulletin, 70, $151-159$.

March, J. G., Schulz, M., \& Zhou, X. (2000). The dynamics of rules: Change in written organizational codes. Stanford, CA: Stanford University Press.

Marcus, B., \& Schuler, H. (2004). Antecedents of counterproductive behavior at work: A general perspective. Journal of Applied Psychology, 89, 647-660.

Mayer, D. M., Caldwell, J., Ford, R. C., Uhl-Bien, M., \& Gresock, A. R. (2007). Should I serve my customer or my supervisor? A relational perspective on pro-social rule breaking. Paper presented at the 67th Annual Meeting of the Academy of Management, Philadelphia, PA.

Morgeson, F. P., \& Humphrey, S. E. (2006). The Work Design Questionnaire (WDQ): Developing and validating a comprehensive measure for assessing job design and the nature of work. Journal of Applied Psychology, 91, 1321-1339.

Morrison, E. W. (2006). Doing the job well: An investigation of pro-social rule breaking. Journal of Management, 32 , 5-28.

Muthén, L. K., \& Muthén, B. O. (1998-2007). Mplus user's guide (5th ed.). Los Angeles, CA: Muthén \& Muthén.

Nunnally, J. C. (1978). Psychometric theory (2nd ed.). New York, NY: McGraw-Hill.

Ones, D. S., Viswesvaran, C., \& Schmidt, F. L. (1993). Comprehensive meta-analysis of integrity test validities: Findings and implications for personnel selection and theories of job performance. Journal of Applied Psychology, 78, 679-703.

Organ, D. (1988). Organizational citizenship behavior: The good soldier syndrome. Lexington, MA: Lexington Books.

Podsakoff, P. M., MacKenzie, S. B., Moorman, R. H., \& Fetter, R. (1990). Transformational leader behaviors and their effects on followers' trust in leader, satisfaction, and organizational citizenship behaviors. The Leadership Quarterly, 1, $107-142$.

Puffer, S. M. (1987). Prosocial behavior, noncompliant behavior, and work performance among commission salespeople. Journal of Applied Psychology, 72, 615-621.

Robinson, S. L., \& Bennett, R. J. (1995). A typology of deviant workplace behaviors: A multidimensional scaling study. Academy of Management Journal, 38, 555-572.

Robinson, S. L., \& O'Leary-Kelly, A. M. (1998). Monkey see, monkey do: The influence of work groups on the antisocial behavior of employees. Academy of Management Journal, 41, 658-672.

Rotundo, M., \& Sackett, P. R. (2002). The relative importance of task, citizenship, and counterproductive performance to global ratings of job performance: A policy-capturing approach. Journal of Applied Psychology, 87, 66-80.

Salancik, G., \& Pfeffer, J. (1978). A social information processing approach to job attitudes and task design. Administrative Science Quarterly, 23, 224-253.

Saucier, G. (1994). Mini-markers: A brief version of Goldberg's unipolar Big-Five markers. Journal of Personality Assessment, $63,506-516$.

Schmitt, N. W., \& Stults, D. M. (1985). Factors defined by negatively keyed items: The results of careless respondents? Applied Psychological Measurement, 9, 367-373.

Schneider, B., White, S. S., \& Paul, M. C. (1998). Linking service climate and customer perceptions of service quality: Test of a causal model. Journal of Applied Psychology, 83, 150-163.

Schulz, M. (2003). Impermanent institutionalization: The duration dependence of organizational rules. Industrial and Corporate Change, 12, 1077-1098.

Skarlicki, D. P., \& Folger, R. (1997). Retaliation in the workplace: The roles of distributive, procedural, and interactional justice. Journal of Applied Psychology, 82, 434-443.

Spector, P. E. (1992). Summated rating scale construction: An introduction. Newbury Park, CA: Sage Publications.

Spreitzer, G. M., \& Sonenshein, S. (2003). Positive deviance and extraordinary organizing. In K. S. Cameron, J. E. Dutton, \& R. E. Quinn (Eds.), Positive organizational scholarship (pp. 207-224). San Francisco, CA: Berrett-Koehler. 
Spreitzer, G. M., \& Sonenshein, S. (2004). Toward the construct definition of positive deviance. American Behavioral Scientist, 47, 828-847.

Staw, B. M., \& Boettger, R. D. (1990). Task revision: A neglected form of work performance. Academy of Management Journal, 33, 534-559.

Stone, T. H., \& Cooper, W. H. (2009). Emerging credits. Leadership Quarterly, 20, 785-798.

Tenbrunsel, A. E., \& Messick, D. M. (2004). Ethical fading: The role of self-deception in unethical behavior. Social Justice Research, 17, 223-236.

Thompson, B. (2004). Exploratory and confirmatory factor analysis: Understanding concepts and applications. Washington, DC: American Psychological Association.

Vardi, Y., \& Weitz, E. (2004). Misbehavior in organizations: Theory, research, and management. Mahwah, NJ: Lawrence Erlbaum Associates.

Vardi, Y., \& Wiener, V. (1996). Misbehavior in organizations: A motivational framework. Organizational Science, 7, 151-165.

Warren, D. E. (2003). Constructive and destructive deviance in organizations. Academy of Management Review, $28,622-632$.

Williams, L. J., \& Anderson, S. E. (1991). Job satisfaction and organizational commitment as predictors of organizational citizenship and in-role behaviors. Journal of Management, 17, 601-617.

Worline, M. C., \& Quinn, R. W. (2003). Courageous principled action. In K. S. Cameron, J. E. Dutton, \& R. E. Quinn (Eds.), Positive organizational scholarship: Foundations of a new discipline (pp. 138-158). San Francisco, CA: Berrett-Koehler Publishers, Inc.

Zellars, K. L., Tepper, B. J., \& Duffy, M. K. (2002). Abusive supervision and subordinates' organizational citizenship behavior. Journal of Applied Psychology, 87, 1068-1076.

Zhou, X. (1993). The dynamics of organizational rules. The American Journal of Sociology, 98, 1134-1166. 